\title{
Curcuma zedoaria (Berg.) Rosc. essential oil and paclitaxel synergistically enhance the apoptosis of SKOV3 cells
}

\author{
YUNXIAO ZHOU ${ }^{1}$, JIE SHEN $^{1}$, LIQUN XIA $^{1}$ and YANLI WANG ${ }^{2}$ \\ Departments of ${ }^{1}$ Gynecology and ${ }^{2}$ Pathology, The First Affiliated Hospital, \\ College of Medicine, Zhejiang University, Hangzhou, Zhejiang 310003, P.R. China
}

Received April 4, 2014; Accepted January 2, 2015

DOI: $10.3892 / \mathrm{mmr} .2015 .3473$

\begin{abstract}
Curcuma zedoaria (Berg.) Rosc. essential oil (CZEO) is the major component of Curcuma zedoaria (Berg.) Rosc., a traditional medicine with antitumor activity. Paclitaxel (PTX) is a first-line chemotherapeutic agent used to treat patients with ovarian cancer. These compounds directly target nuclear DNA, in order to suppress or inhibit tumor cell growth. The present study aimed to determine the synergistic antitumor effects of CZEO and PTX on the SKOV3 human ovarian cancer cell line. SKOV3 cells were treated with CZEO, PTX or a combination of the two and cell viability was detected using cell counting kit- 8 . In addition, flow cytometry was used to determined cell apoptosis as well as for cell cycle analysis. The morphological changes of apoptosis were assessed using Hoechst 33342 staining and the expression levels of apoptotic pathway proteins, including caspase-3 and poly (ADP-ribose) polymerase (PARP), were quantified using western blot analysis. The cell viability assay indicated that either of these compounds alone or in combination suppressed the growth of SKOV3 cells. Furthermore, flow cytometric analysis indicated that treatment with a combination of CZEO and PTX resulted in increased inhibition of proliferation and induction of apoptosis of SKOV3 cells, as compared with treatment with either of the compounds alone. In addition, the protein expression levels of caspase-3 were increased following treatment with a combination of CZEO and PTX. The results of the present study suggested that CZEO and PTX synergistically enhanced the inhibition of SKOV3 proliferation, and the possible underlying mechanism may be the induction of cell apoptosis and cell cycle arrest. This therefore indicated that PTX supplemented with CZEO may be an effective treatment strategy to decrease the dose and toxicity of PTX.
\end{abstract}

Correspondence to: Dr Yunxiao Zhou, Department of Gynecology, The First Affiliated Hospital, College of Medicine, Zhejiang University, 79 Qingchun Road, Hangzhou, Zhejiang 310003, P.R. China

E-mail: yunxiaozhouyx@163.com

Key words: Curcuma zedoaria (Berg.) Rosc. essential oil, paclitaxel, ovarian cancer, cell apoptosis, cell cycle

\section{Introduction}

Paclitaxel (PTX) is a first-line chemotherapeutic agent used to treat patients with ovarian cancer. PTX is a novel microtubule-damaging agent that stabilizes the structure of tubulin, by promoting its polymerization and suppressing its depolymerization (1). Therefore, PTX effectively inhibits cellular mitosis (2). Curcuma zedoaria (Berg.) Rosc. is a traditional medicine that is used to treat flatulence, dyspepsia, menstrual disorders, cough and fever (3). Furthermore, previous studies have demonstrated its anticancer action (4-6). A major component of Curcuma zedoaria (Berg.) Rosc. is essential oil (3,7-9). PTX and Curcuma zedoaria (Berg.) Rosc. essential oil (CZEO) are considered to be potential anticancer drugs. These compounds directly target nuclear DNA, in order to suppress or inhibit tumor cell growth. Furthermore, tumor immunogenicity can be increased by either treatment, resulting in the induction of a stronger cytotoxic response to tumor cells (10).

Apoptosis, also known as programmed cell death, is an active intracellular death program that has a key role in the maintenance of organisms (11). Caspases, a family of cysteine proteases, are the key executors of apoptosis (12). Caspase-3 is situated at pivotal junctions in apoptosis pathways and its activation leads to a series of cellular events (13). Poly adenosine diphosphate-ribose polymerase (PARP), a nuclear protein involved in the DNA damage response, is a well-known substrate for caspase-3 cleavage during apoptosis (14).

In the present study, in order to explore the antitumor effects of the combined treatment of PTX and CZEO, an in vitro experiment was conducted using the SKOV3 human ovarian cancer cell line. The effects of the treatment on cell growth were determined, and the underlying mechanisms were investigated.

\section{Materials and methods}

Chemicals and reagents. Cell Counting kit-8 (CCK-8) was purchased from Dojindo Molecular Technologies, Inc. (Kumamoto, Japan). RPMI-1640 media was purchased from Thermo Fisher Scientific (Beijing, China), and fetal bovine serum (FBS) was obtained from Gibco Life Technologies (Carlsbad, CA, USA). Propidium iodide (PI) was purchased from Sigma-Aldrich (St. Louis, MO, USA). 
Curcuma zedoaria (Berg.) Rosc. essential oil. Zedoray Turmeric Oil Injection, containing $0.1 \mathrm{~g} / 10 \mathrm{ml}$ CZEO, was purchased from Xuzhou Lai'en Pharmaceutical Co., Ltd (Xuzhou, China). The main components of CZEO are neocurdione, curdione, germacrone, curzerene, furanodiene, $\gamma$-elemene and 8,9-dehydro-9-formyl-cycloisolongifolene (15).

Cell lines and cell culture. The SKOV3 human ovarian cancer cells were purchased from the Cell Bank of the Cinese Academy of Sciences (Shanghai, China). The cells were cultured in RPMI-1640 supplemented with 10\% heat-inactivated FBS, $100 \mathrm{U} / \mathrm{ml}$ penicillin and $100 \mu \mathrm{g} / \mathrm{ml}$ streptomycin (Gibco Life Technologies), at $37^{\circ} \mathrm{C}$ in a humidified atmosphere containing $5 \% \mathrm{CO}_{2}$.

Cell proliferation assay. The SKOV3 cells were dispersed in culture medium supplemented with $10 \%$ FBS and were seeded in a 96-well plate at a density of $2 \times 10^{4}$ cells $/ \mathrm{ml}$. The cells were then treated with PTX (10 nM; Xi'an Sanjiang Bio-Engineering Co. Ltd, Xi'an, China), CZEO $(62.5 \mu \mathrm{g} / \mathrm{ml})$ or a combination of the two for $48 \mathrm{~h}$, following $24 \mathrm{~h}$ growth. Cell in the control group were treated with $0.2 \mathrm{ml}$ phosphate-buffered saline (PBS). A total of $10 \mu \mathrm{l}$ CCK-8 was added to each well, and the cells were then cultured in an incubator for a further $3 \mathrm{~h}$. The optical density (OD) of the cells was measured at $490 \mathrm{~nm}$ using a microplate spectrophotometer (Spectramax 190; Molecular Devices Corp., Sunnyvale, CA, USA). Each concentration corresponds to three parallel wells for detection. The cell viability was calculated as follows: Cell viability $=\left(\mathrm{OD}_{\text {treated }}\right.$ group $\left.-\mathrm{OD}_{\text {blank }}\right) /\left(\mathrm{OD}_{\text {control }}-\mathrm{OD}_{\text {blank }}\right) \times 100$. The interaction between PTK and CZEO was analyzed using CalcuSyn 2.0 software (Biosoft, Cambridge, UK), using the Chou and Talalay method (16). The combination index (CI) was determined on the basis of the isobologram analysis: $\mathrm{CI}<1$, synergistic effect; $\mathrm{CI}=1$, additive effect; and $\mathrm{CI}>1$, antagonistic effect.

Hoechst 33342 staining. The SKOV 3 cells $\left(5 \times 10^{5}\right.$ cells $\left./ \mathrm{ml}\right)$ were seeded in six-well plates, and cultured overnight. Following treatment with PTX $(10 \mathrm{nM}), \mathrm{CZEO}(62.5 \mu \mathrm{g} / \mathrm{ml})$ or a combination of the two for $24-48 \mathrm{~h}$ in a $37^{\circ} \mathrm{C}$ incubator containing $5 \% \mathrm{CO}_{2}$, the cells were incubated with Hoechst $33342(5 \mu \mathrm{l}$; Sigma-Aldrich) for $30 \mathrm{~min}$. Hoechst 33342-stained cell nuclei were observed using an inverted fluorescence microscope (BX60; Olympus Optical Co., Tokyo, Japan), and images were captured with a confocal microscope (LSM510; Carl Zeiss AG, Oberkochen, Germany).

Detection of apoptosis by flow cytometry. The SKOV3 cells $\left(5 \times 10^{5}\right.$ cells $\left./ \mathrm{ml}\right)$ were seeded in six-well plates and cultured for $12 \mathrm{~h}$. Following treatment of the cells with PTX, CZEO, or a combination of the two for $48 \mathrm{~h}$ in a $37^{\circ} \mathrm{C}$ incubator containing $5 \% \mathrm{CO}_{2}$, the cells were collected and washed twice with cold PBS in order to remove the medium. The cells were then resuspended in $100 \mu \mathrm{l}$ of $1 \mathrm{X}$ binding buffer (Invitrogen Life Technologies, Carlsbad, CA, USA), prior to the addition of $5 \mu \mathrm{l}$ Annexin-V (Invitrogen Life Technologies) and $1 \mu \mathrm{l}$ propidium iodide (PI; Sigma-Aldrich) and incubation in the dark on ice. Finally, $400 \mu \mathrm{l}$ of $1 \mathrm{X}$ binding buffer was added to the cells and they were analyzed by flow cytometry using a BD FACSAria cell sorter (Becton-Dickinson, San Jose, CA, USA).
Cell cycle analysis by flow cytometry. The SKOV3 cells were seeded in six-well plates and treated as mentioned in the previous section. The cells were then harvested, washed twice with PBS and resuspended in $0.3 \mathrm{ml}$ PBS. RNase A (Roche, Indianapolis, IN, USA) was added, in order to digest the cells for $30 \mathrm{~min}$ at $37^{\circ} \mathrm{C}$, after which the cells were collected and washed twice with PBS. The reaction was terminated by placing the mixture on ice. PI was added to the cells in the dark, in order to prepare the samples for flow cytometry.

Western blotting of key signal proteins caspase-3 and PARP for apoptosis. The SKOV3 cells $\left(5 \times 10^{5}\right.$ cells $\left./ \mathrm{ml}\right)$ were seeded in $60 \mathrm{~mm}$ culture dishes in the presence of PTX, CZEO, or a combination of the two for $48 \mathrm{~h}$, and cultured in a $37^{\circ} \mathrm{C}$ incubator containing $5 \% \mathrm{CO}_{2}$. The cells were collected according to the standard western blotting procedure. The protein samples were used straight after protein concentration determination, or were stored at $-20^{\circ} \mathrm{C}$ until further use.

Protein concentration of the samples was determined using bicinchoninic acid protein reagent .(Pierce Biotechnology, Inc., Rockford, IL, USA). The protein samples were separated by SDS electrophoresis on polyacrylamide gels and transferred to a nitrocellulose membrane (Millipore, Billerica, MA, USA). The membranes were then blocked in $5 \%$ bovine serum albumin (Sigma-Aldrich) for $3 \mathrm{~h}$ at room temperature, followed by incubation for $2 \mathrm{~h}$ at room temperature with primary antibodies (rabbit polyclonal anti-PARP and anti-caspase-3; 1:1,000; Cell Signaling Technology, Inc., Beverly, MA, USA). The membranes were washed (3x10 min) in tris-buffered saline with Tween ${ }^{\circledR}$ (TBST) and were then incubated with a horseradish peroxidase-conjugated sheep anti-rabbit secondary antibody (1:2,000; Santa Cruz Biotechnology, Inc., Dallas, TX, USA) for $1 \mathrm{~h}$ at room temperature, followed by further washing (3x10 min) with TBST. Immunoblot signals were detected by Odyssey Infrared Imaging v1.2 system (LI-COR Biosciences, Lincoln, NE, USA).

Statistical analysis. All of the data are expressed as the mean \pm standard error of the mean. Student's t-test was used to determine the statistical significance between two observations and a one-way analysis of variance followed by the Bonferroni test were used for the multiple comparisons. Statistical analyses were performed using SPSS version 11.0 (SPSS Inc., Chicago, IL, USA). P $\leq 0.05$ was considered to indicate a statistically significant difference.

\section{Results}

Treatment with a combination of CZEO and PTX significantly suppresses proliferation of SKOV3 cells. Treatment with CZEO or PTX significantly inhibited the viability of SKOV3 cells in a dose-dependent manner, at concentrations between 2.5 and $40 \mathrm{nM}$ PTX, and between 15.625 and $250 \mu \mathrm{g} / \mathrm{ml}$ CZEO (Fig. 1A). Furthermore, treatment with a combination of CZEO and PTX enhanced the suppressive effect on the SKOV3 cells (Fig. 1B; confidence interval, 0.526 to 0.705 ).

Treatment with a combination of CZEO and PTX enhances the apoptosis of SKOV3 cells and induces cell cycle arrest at $G_{2} / M$ phase. Flow cytometry was used to detect apoptosis, following 
A

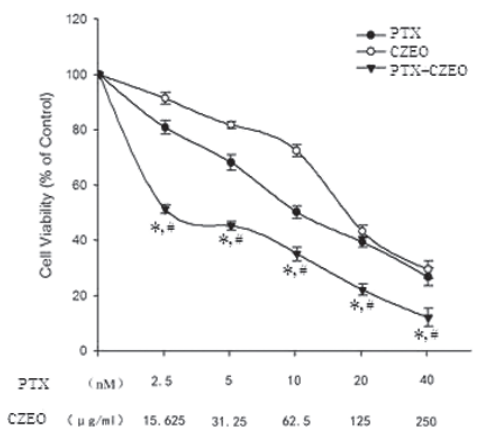

B

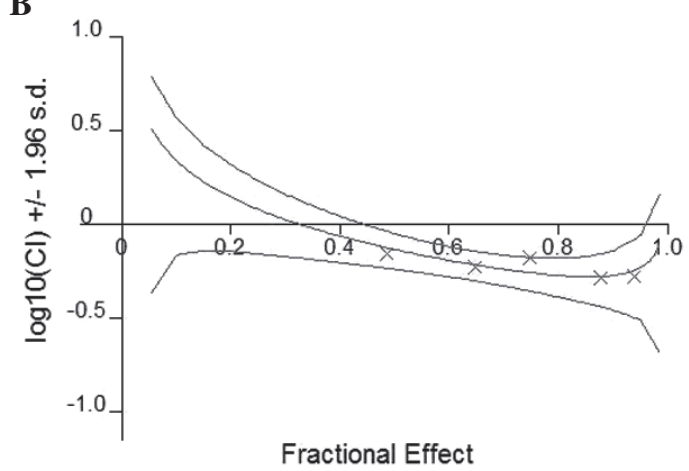

Figure 1. Treatment with a combination of CZEO and PTX significantly inhibited the proliferation of SKOV3 human ovarian cancer cells. (A) Survival rates of SKOV3, as detected using Cell Counting kit-8 ("P<0.05 vs. PTX; ${ }^{*} \mathrm{P}<0.05$ vs. CZEO). (B) Synergistic effects of CZEO and PTX, as analyzed using CalcuSyn software. The middle line represents curve fitting of the CI values as a function of fractional effect and data points are indicated by ' $\mathrm{X}$ '. The other two lines represent the $95 \%$ confidence interval of the values. $\mathrm{CI}<1$ indicates a synergistic effect. PTX, paclitaxel; CZEO, Curcuma zedoaria (Berg.) Rosc. essential oil; CI, combination index.
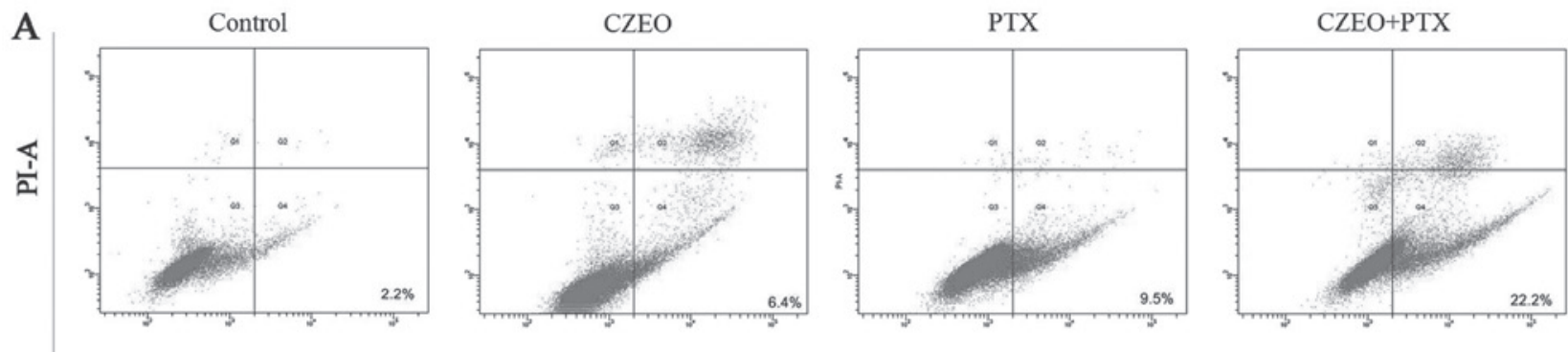

FITC-A

B

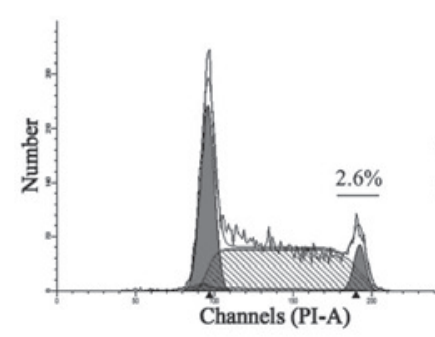

CZEO

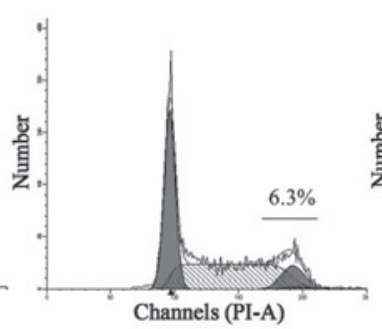

PTX

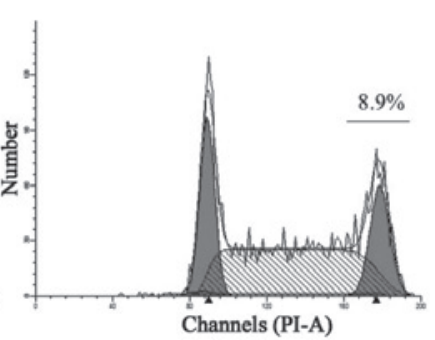

PTX+CZEO

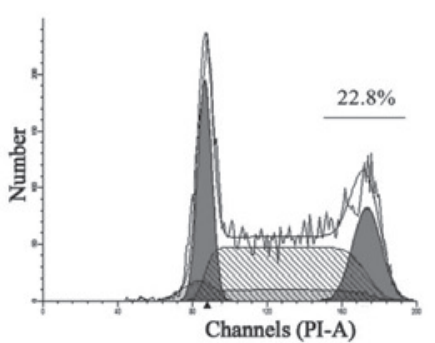

Figure 2. Effect of the combined treatment of PTX and CZEO on cell cycle distribution and apoptosis of SKOV3 human ovarian cancer cells. (A) Apoptosis and (B) cell cycle distribution were detected using flow cytometry. PBS, phosphate-buffered saline; PTX, paclitaxel; CZEO, Curcuma zedoaria (Berg.) Rosc. essential oil; FITC, fluorescein isothiocyanate; PI, propidium iodide.

treatment of the SKOV3 cells with CZEO $(62.5 \mu \mathrm{g} / \mathrm{ml})$, PTX $(10 \mathrm{nM})$, or a combination of the two for $48 \mathrm{~h}$. The cells were collected for dual staining using Annexin V/PI and then underwent flow cytometry. The cells stained with Annexin V but not PI were considered to be in the early-apoptotic phase. Treatment with a combination of CZEO and PTX significantly enhanced the rate of apoptosis (Fig. 2A). The rate of apoptosis of the cells treated with CZEO $(62.5 \mu \mathrm{g} / \mathrm{ml})$, PTX (10 nM) and a combination of the two was $6.4 \%, 9.5 \%$ and $22.2 \%$, respectively.

Flow cytometry was used to perform a cell cycle analysis, following treatment of the SKOV3 cells with CZEO
$(62.5 \mu \mathrm{g} / \mathrm{ml})$, PTX $(10 \mathrm{nM})$, or a combination of the two for $24 \mathrm{~h}$. The number of cells arrested at $\mathrm{G}_{2} / \mathrm{M}$ phase were significantly increased (Fig. 2B), which may be partially attributed to the anti-proliferative effects of CZEO and PTX.

Morphological changes. The SKOV3 cells exhibited morphological changes characteristic of apoptosis following treatment with CZEO $(62.5 \mu \mathrm{g} / \mathrm{ml})$, PTX $(10 \mathrm{nM})$, or a combination of the two. A microscopic observation demonstrated that the cells treated with CZEO $(62.5 \mu \mathrm{g} / \mathrm{ml})$, PTX $(10 \mathrm{nM})$, or a combination of the two for $48 \mathrm{~h}$ had significantly reduced growth and exhibited morphological changes characteristic of apoptosis, 

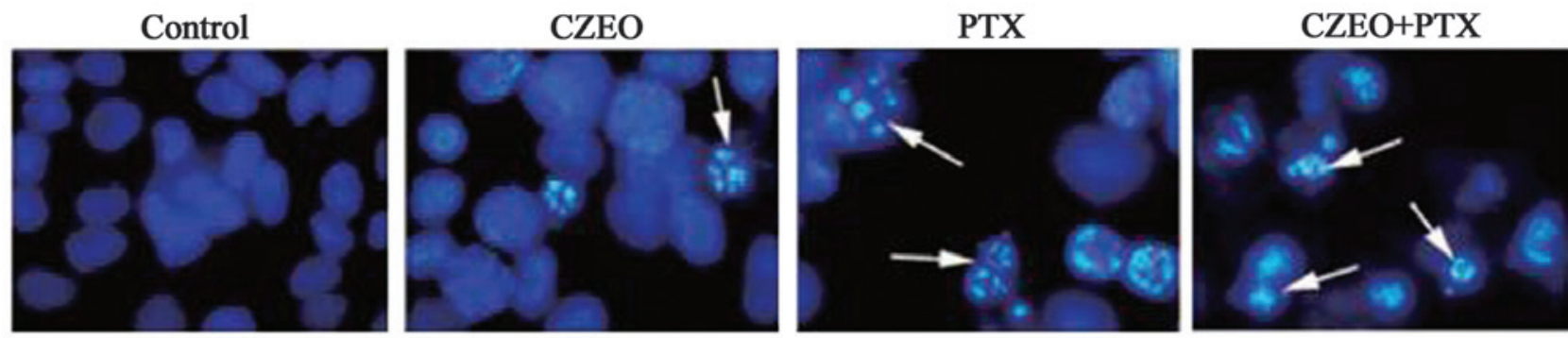

Figure 3. Hoechst 33342 staining was performed to detect the apoptosis of SKOV3 human ovarian cancer cells. Arrows indicate the cells which are immunoreactive for Hoechst 33342 staining (magnification, x1200). PTX, paclitaxel; CZEO, Curcuma zedoaria (Berg.) Rosc. essential oil.

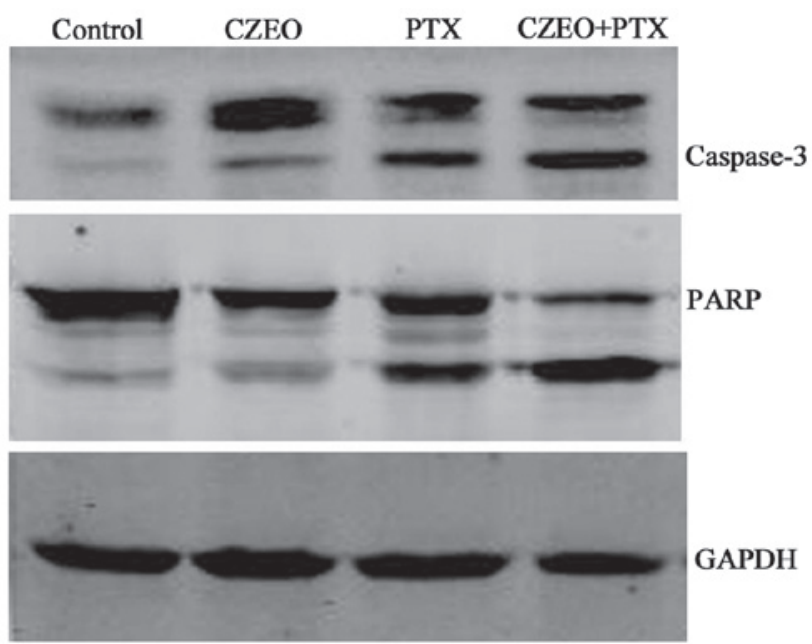

Figure 4. Expression levels of proteins involved in the apoptotic pathway, as detected by western blotting. PARP, poly (ADP-ribose) polymerase; PTX, paclitaxel; CZEO, Curcuma zedoaria (Berg.) Rosc. essential oil.

including widespread chromatin condensation, exocytosis, and condensation and fragmentation of nuclei (Fig. 3).

Hoechst 33342 staining was also performed to detect apoptosis following treatment with CZEO $(62.5 \mu \mathrm{g} / \mathrm{ml})$, PTX $(10 \mathrm{nM})$ or a combination of the two for $48 \mathrm{~h}$. The untreated control cells exhibited normal chromatin without condensation or fragmentation, with no bright staining in the nuclei, thus indicating the absence of dying cells. Whereas, the treated cells exhibited significantly condensed and fragmented chromatin, disintegration of nuclei and formation of apoptotic bodies.

Relative expression levels of apoptotic pathway proteins detected by western blotting. Following treatment with CZEO $(62.5 \mu \mathrm{g} / \mathrm{ml})$, PTX $(10 \mathrm{nM})$, or a combination of the two for $24 \mathrm{~h}$, the cells were harvested for western blotting, in order to detect the expression levels of proteins involved in the apoptotic pathway. Treatment with a combination of CZEO and PTX activated caspase-3, to form a cleaved product of the substrate PARP (Fig. 4).

\section{Discussion}

Ovarian cancer is one of the three most common malignant cancers that occur within the female reproductive tract, which poses a severe threat to the health of the female population. The incidence of ovarian cancer has increased annually during the past two decades (17). The early stages of ovarian cancer can be effectively treated with chemotherapy; however, $70 \%$ of ovarian cancers are diagnosed at a late stage (18), which severely effects the life quality and mortality rates of patients, since the cancer cells develop resistance to drugs, such as PTX (19). Cyto-reductive surgery is the first-line therapy for patients with all stages of ovarian cancer, which is used in combination with chemotherapy or radiotherapy for patients with late stage or recurrent ovarian cancer, so as to improve their quality of life and chances of survival (20).

PTX is a potent drug of natural origin, which is isolated from the bark of the Pacific yew (Taxus brevifolia) (21), and is considered the first-line antitumor drug for ovarian cancer. However, the success of PTX chemotherapy in treating ovarian cancer is limited, due to its extreme toxicity $(22,23)$. Therefore, developing a novel therapeutic strategy with higher therapeutic efficacy and lower toxicity is required.

Previous studies regarding combination chemotherapy have focused on identifying natural compounds that may increase the therapeutic index. Cang et al (24) reported that phenethyl isothiocyanate enhanced the apoptosis and $\alpha$-tubulin hyperacetylation abilities of PTX in MCF7 and MDA-MB-231 breast cancer cell lines. Yang et al (25) previously demonstrated that luteolin could enhance PTX-induced apoptosis in MDA-MB-231 human breast cancer cells, by blocking signal transducer and activator of transcription 3. Hossein et al (19) showed that PectaSol-C modified citrus pectin could sensitize ovarian cancer cells to PTX by inducing apoptosis, which may lead to an accumulation of cells in the subG $\mathrm{G}_{1}$ and $\mathrm{G}_{1}$ phases, and cleavage of caspase-3 (24-27). Numerous studies have reported that CZEO is a promising antitumor drug, which has a direct cytotoxic effect that inhibits tumor cell growth and proliferation, disrupts nuclear metabolism, inhibits angiogenesis and impairs the membrane potential, all of which can be lethal to cancer cells $(3,15,28)$. To the best of our knowledge, the present study was the first to demonstrate the effect of the combination of CZEO and PTX in suppressing cancer cell growth.

The cell viability assay demonstrated that the tumor survival rate of the cells decreased following treatment with CZEO, in a dose-dependent manner, which is concordant with the findings of Chen et al (3) and Chen et al (15). Furthermore, the inhibitory effect was increased by treatment with the combination of CZEO and PTX. In addition, the combination also enhanced the rate of apoptosis, which was demonstrated by the observation of morphological changes. These results indicate that it may be possible to reduce the side effects of PTX whilst enhancing its clinical efficacy by using it in combination with CZEO. 
PTX can arrest the cell cycle at the $\mathrm{G}_{2} / \mathrm{M}$ phase and induce caspase-3 enzymatic activity (29-32). In the present study, treatment with the combination of CZEO and PTX increased the accumulation of cells in the $\mathrm{G}_{2} / \mathrm{M}$ phase, and the expression levels of caspase-3. These results indicate that the synergistic antitumor effects of CZEO and PTX are achieved by inducing apoptosis and arresting the cell cycle at $\mathrm{G}_{2} / \mathrm{M}$ phase.

In conclusion, the present study demonstrated that CZEO can sensitize ovarian cancer cells to PTX, through inducing apoptosis, which was the result of the accumulation of cells in the $\mathrm{G}_{2} / \mathrm{M}$ phase, and cleavage of caspase-3. These results suggest that PTX supplemented with CZEO may be an effective treatment strategy to decrease the dose and toxicity of PTX. Further studies are required to clarify the signaling pathways and key molecules underlying the effects of a combination of CZEO and PTX in human ovarian cancer.

\section{Acknowledgements}

The present study was supported by the Zhejiang Traditional Chinese Medicine Grant, China (grant no. 2010ZA 064).

\section{References}

1. Blagosklonny MV and Fojo T: Molecular effects of paclitaxel: myths and reality (a critical review). Int J Cancer 83: 151-156, 1999

2. Neijt JP, Engelholm SA Tuxen MK et al: Exploratory phase III study of paclitaxel and cisplatin versus paclitaxel and carboplatin in advanced ovarian cancer. J Clin Oncol 18: 3084-3092, 2000.

3. Chen W, Lu Y, Gao M, Wu J, Wang A and Shi R: Anti-angiogenesis effect of essential oil from Curcuma zedoaria in vitro and in vivo. J Ethnopharmacol 133: 220-226, 2011.

4. Lobo R, Prabhu K S, Shirwaikar A and Shirwaikar A: Curcuma zedoaria Rosc. (white turmeric): a review of its chemical, pharmacological and ethnomedicinal properties. J Pharm Pharmacol 61: 13-21, 2009.

5. Lakshmi S, Padmaja G and Remani P: Antitumour effects of isocurcumenol isolated from Curcuma zedoaria rhizomes on human and murine cancer cells. International Journal of Medicinal Chemistry 2011:2011, 2011.

6. Kim KI, Kim JW, Hong BS, et al: Antitumor, genotoxicity and anticlastogenic activities of polysaccharide from Curcuma zedoaria. Mol Cells 10: 392-398, 2000.

7. Seo WG, Hwang JC, Kang SK, et al: Suppressive effect of Zedoariae rhizoma on pulmonary metastasis of B16 melanoma cells. J Ethnopharmacol 101: 249-257, 2005.

8. Shin Y and Lee Y: Cytotoxic activity from Curcuma zedoaria through mitochondrial activation on ovarian cancer cells. Toxicol Res 29: 257-261, 2013

9. Wu WY, Luo YJ and Cheng JH: Zedoary turmeric oil inhibits tranplantal hepatoma in rat via hepatic artery perfusion. Shi Jie Hua Ren Xiao Hua Za Zhi 11: 260-263, 1998

10. Giampietri A, Bonmassar A, Puccetti P, et al: Drug-mediated increase of tumor immunogenicity in vivo for a new approach to experimental cancer immunotherapy. Cancer Res 41: 681-687, 1981.

11. Elmore S. Apoptosis: a review of programmed cell death. Toxicol Pathol 35: 495-516, 2007

12. Jiang $\mathrm{C}$, Wang $\mathrm{Z}$, Ganther $\mathrm{H}$, et al: Caspases as key executors of methyl selenium-induced apoptosis (anoikis) of DU-145 prostate cancer cells. Cancer Res 61: 3062-3070, 2001.

13. Lakhani S A, Masud A, Kuida K, et al: Caspases 3 and 7: key mediators of mitochondrial events of apoptosis. Science 311: $847-851,2006$
14. Chowdhry MF, Vohra HA and Galiñanes M: Diabetes increases apoptosis and necrosis in both ischemic and nonischemic human myocardium: Role of caspases and poly-adenosine diphosphateribose polymerase. J Thorac Cardiovasc Surg 134: 124-131, 2007.

15. Chen CC, Chen Y, Hsi YT, et al: Chemical constituents and anticancer activity of Curcuma zedoaria roscoe essential oil against non-small cell lung carcinoma cells in vitro and in vivo. J Agric Food Chem 61: 11418-11427, 2013.

16. Chou TC and Talalay P: Quantitative analysis of dose-effect relationships: the combined effects of multiple drugs or enzyme inhibitors. Adv Enzyme Regul 22: 27-55, 1984.

17. Smith RA, Brooks D, Cokkinides V, et al: Cancer screening in the United States, 2013: a review of current American Cancer Society guidelines, current issues in cancer screening, and new guidance on cervical cancer screening and lung cancer screening. CA Cancer J Clin 63: 87-105, 2013.

18. McGuire V, Jesser CA and Whittemore AS: Survival among U.S. woman with invasive epithelical ovarian cancer. Gynecol Oncol 84: 399-403, 2002

19. Hossein G, Keshavarz M, Ahmadi S and Naderi N: Synergistic effects of PectaSol-C modified citrus pectin an inhibitor of Galectin-3 and paclitaxel on apoptosis of human SKOV-3 ovarian cancer cells. Asian Pac J Cancer Prev 14: 7561-7568, 2013.

20. Kushner DM, Connor JP, Sanchez F, et al; Wisconsin Oncology Network: Weekly docetaxel and carboplatin for recurrent ovarian and peritoneal cancer: a phase II trial. Gynecol Oncol 105: 358-364, 2007.

21. Wani MC, Taylor HL, Wall ME, Coggon P and McPhail AT: Plant antitumor agents. VI. The isolation and structure of taxol, a novel antileukemic and antitumor agent from Taxus brevifolia. J Am Chem Soc 93: 2325-2357, 1971.

22. Maier-Lenz H, Hauns B, Haering B, et al: Phase I study of paclitaxel administered as a 1-hour infusion: toxicity and pharmacokinetics. Semin Oncol 24: S16-S19, 1997.

23. Scripture CD, Figg WD and Sparreboom A: Peripheral neuropathy induced by paclitaxel: recent insights and future perspectives. Curr Neuropharmacol 4: 165-172, 2006.

24. Cang S, Ma Y, Chiao JW and Liu D: Phenethyl isothiocyanate and paclitaxel synergistically enhanced apoptosis and alpha-tubulin hyperacetylation in breast cancer cells. Exp Hematol Oncol 3: 5, 2014.

25. Yang MY, Wang CJ, Chen NF, Ho WH, Lu FJ and Tseng TH: Luteolin enhances paclitaxel-induced apoptosis in human breast cancer MDA-MB-231 cells by blocking STAT3. Chem Biol Interact 213: 60-68, 2014.

26. Kang H, Lee SH, Price JE and Kim LS: Curcumin suppresses the paclitaxel-induced nuclear factor-kappaB in breast cancer cells and potentiates the growth inhibitory effect of paclitaxel in a breast cancer nude mice model. Breast J 15: 223-229, 2009.

27. Kuo HC, Lee HJ, Hu CC, Shun HI and Tseng TH: Enhancement of esculetin on Taxol-induced apoptosis in human hepatoma HepG2 cells. Toxicol Appl Pharmacol 210: 55-62, 2006.

28. Long KJ, Han FJ, Wu XK and Wang XY: Effects of Zedoary turmeric oil injection on SKOV3 cell proliferation and pathological morphological changes in ovarian cancer. World Journal of Integrated Traditional and Western Medicine 6: 660-662, 2011.

29. George J, Banik NL and Ray SK: Molecular Mechanisms of Taxol for Induction of Cell Death in Glioblastomas. In: Glioblastoma: Molecular Mechanisms of Pathogenesis and Current Therapeutic Strategies. Ray SK (ed). Springer, New York, pp283-298, 2010.

30. Gonçalves A, Braguer D, Carles G, André N, Prevôt C and Briand C: Caspase-8 activation independent of CD95/CD95-L interaction during paclitaxel-induced apoptosis in human colon cancer cells (HT29-D4). Biochem Pharmacol 60: 1579-1584, 2000

31. Perkins C, Kim CN, Fang G and Bhalla KN: Overexpression of Apaf-1 promotes apoptosis of untreated and paclitaxel- or etoposide-treated HL-60 cells. Cancer Res 58: 4561-4566, 1998.

32. Weigel TL, Lotze MT, Kim PK, Amoscato AA, Luketich JD and Odoux C: Paclitaxel-induced apoptosis in non-small cell lung cancer cell lines is associated with increased caspase-3 activity. J Thorac Cardiovasc Surg 119: 795-803, 2000. 